\title{
GIS-Based Model for Mapping Malaria Risk under Climate Change Case Study: Burundi
}

\author{
Mahmoud A. Hassaan1, Mohamed A. Abdrabo', Prosper Masabarakiza² \\ ${ }^{1}$ Alexandria Research Center for Adaptation to Climate Change (ARCA), Institute of Graduate Studies and Research, \\ Alexandria University, Alexandria, Egypt \\ ${ }^{2}$ National Institute of Public Health (INSP), Bujumbura, Burundi \\ Email: mhassaan@hotmail.com
}

How to cite this paper: Hassaan, M.A. Abdrabo, M.A. and Masabarakiza, P. (2017) GIS-Based Model for Mapping Malaria Risk under Climate Change Case Study: Burundi. Journal of Geoscience and Environment Protection, 5, 102-117.

https://doi.org/10.4236/gep.2017.511008

Received: October 7, 2017

Accepted: November 10, 2017

Published: November 13, 2017

Copyright (C) 2017 by authors and Scientific Research Publishing Inc. This work is licensed under the Creative Commons Attribution International License (CC BY 4.0).

http://creativecommons.org/licenses/by/4.0/

\begin{abstract}
Malaria is one of the largest problems threatening global public health that is expected to increase in the future under climate change due to associated warming and wetter conditions. This will exacerbate disease burden in $\mathrm{Bu}-$ rundi as one of sub-Saharan African countries, where 2 million cases of malaria were reported in 2015. This highlights the need for developing a methodology for mapping malaria risk under climate change and delineating those regions that may potentially experience malaria epidemics in the future. Malaria transmission and distribution are generally determined by a wide range of climatic, topographic and socioeconomic factors. The paper in hand is intended to map malaria risk in Burundi under climate change up to 2050. For this purpose, a GIS-based model was developed for mapping malaria as a function of various climatic and topographic determinants of malaria. The developed GIS-model was used in mapping malaria risk under current climatic conditions. Thereafter, the produced risk map was validated compared to malaria morbidity data in Burundi at health district level. Finally, the GIS-model was applied to map malaria risk in the future under RCPs 2.6 and 8.5 scenarios up to 2050 . It was found that about $34.6 \%$ and $44 \%$ of Burundi land surface will be highly vulnerable to malaria risk by 2050 under RCPs 2.6 and 8.5 scenario, respectively. Also, it was noted that such highly vulnerable areas are distributed mainly in northern parts of the country. The suggested GIS-based model for mapping malaria risk under climate change can contribute largely to more informed decision-making and policy making process in terms of planning for intervention and control malaria risk. This in turn can support reducing disease burden and improving resilience to climate change.
\end{abstract}

\section{Keywords}

Malaria Risk, GIS, Mapping Vulnerability, Burundi 


\section{Introduction}

Malaria represents one of the largest problems threatening global public health [1] with total cases exceeding 212 million worldwide in 2015, of which $90 \%$ were in Africa. Moreover, Malaria caused 429 thousand deaths globally in 2015 [2]. In this respect, it was estimate that Malaria was the seventh leading cause of death in low-income countries by 2015 , leading to 34.5 causes of deaths per 100,000 of population on average in these countries [3]. As one of vector-borne disease systems, malaria is caused by Plasmodium parasites that transmitted by Anopheles mosquito. Malaria transmission and distribution are generally determined by a wide range of climatic, topographic and socioeconomic factors [4] [5]. While both climatic and topographic factors determine the suitable habitats for Plasmodium and Anopheles, socioeconomic factors are more relevant to adaptive capacities of individuals or communities and consequently determine their vulnerability to malaria.

A wide range of research work was undertaken to recognize the various factors underlying malaria risk in different countries [6]. The contribution of climate in malaria transmission was already recognized [7] and the association between epidemics of malaria and climate was evidenced in different regions worldwide in particular in sub-Saharan African countries [1] [8] [9], Latin America [10] and Asia [11]. Generally, malaria incidence increases with warm and wet conditions, where higher temperature leads to increasing malaria incidence as it contributes to shortening extrinsic incubation period of Anopheles mosquito [8] [12]. Generally, it was suggested that the optimum temperature for Anopheles mosquito and parasite development ranges between $20^{\circ} \mathrm{C}$ and $30^{\circ} \mathrm{C}$ and they are subjected to thermal death if temperature rises above $40^{\circ} \mathrm{C}$ or drops below $16^{\circ} \mathrm{C}$ [13]. Yet, it is worth mentioning that the impact of temperature on malaria cannot be fully explained only by mean temperature [14]. Actually, diurnal temperature range has significant impacts on malaria transmission, where more diurnal temperature range in relatively cold conditions, with mean temperature below $21^{\circ} \mathrm{C}$, may increase malaria transmission as it accelerates mosquito development. Meanwhile, more diurnal temperature range in warmer conditions, with mean temperature above $21^{\circ} \mathrm{C}$, may lead usually to decrease malaria transmission as it may slow-down mosquito development [14] [15]. Also, malaria incidence strongly associated with wet conditions, higher levels of rainfall [8] or relative humidity [4] that usually support Anopheles mosquito to complete their life cycle [10]. In this respect, $80 \mathrm{~mm}$ per month of rainfall for at least five months was suggested as a threshold limit that is sufficient to malaria transmission [4].

Moreover, malaria incidence is significantly affected by some topographic factors such as altitude, slope and land cover. In this respect, the negative relationship between the risk of malaria infection and altitude was well-recognized. For instance, it was argued that malaria morbidity was significantly less prevalent in the highlands that experience relatively cold conditions compared to 
lowlands [16]. Such low temperature in high altitude limits parasite development and consequently restricts the spread of malaria there [12]. Similarly, malaria risk is negatively associated with slope, where breeding sites of mosquitos are more likely to be in gentle slopes and planes [17]. Usually, katabatic wind in steep slopes and a relatively cold temperature during nights restrict dispersion of mosquitos into higher altitudes [17] [18]. Also, malaria risk increases in some patterns of land cover that are dominated by wetlands, farmlands and regularly flooded land. Such type of land covers provides suitable sites for Anopheles mosquitos to complete their life cycle [10] [12] [19].

As a result of sensitivity of malaria transmission to climate and topography, malaria was defined as a highly climate sensitive disease [10] and an environmental related disease [20]. Such sensitivity, also, implies that the great potentials for mapping malaria risk through various climatic and topographic variables that determine malaria transmission. Recently, mapping malaria has been promoted by increasing data availability, improved insight into environmental covariates of malaria risk, advances in analytical techniques [21] and availability of affordable Geographical Information Systems (GIS) software [4]. The application of GIS was not restricted only to mapping malaria incidence but extended also to include assessing the relationship between malaria and underlying factors, developing malaria early warning systems [13] and planning for malaria control programs [22]. This was motivated by the nature of data on malaria incidence and underlying climatic, topographic and socioeconomic factors are spatial variables that can be modeled and manipulated through GIS due the great capabilities of such systems in terms of handling and analyzing spatial data. In this respect, it is worth mentioning that the successful application of GIS in mapping malaria and planning for control programs depends largely on availability of accurate and updated data on malaria cases [22].

Malaria is one of the main health issues in Burundi in terms of morbidity, mortality and associated sever economic costs [8]. In 2015, Burundi had 2 million cases of malaria, which led to about 5600 deaths [2]. Due to its significant magnitude, malaria in Burundi was considered repeatedly. For example, Nkurunziza et al. (2010) and Nkurunziza et al. (2011) attempted to provide better understanding on various influencing climatic factors [6] [8]. More recently, Moise et al. (2016) examined the spatial patterns of malaria morbidity [23]. It was projected that climate change will have significant impacts on expanding spatial extent of the areas vulnerable to malaria risk [24] [25] as a result of expected warming and increasing humidity [26]. However, none of the previous research work considered the potential impacts of climate change on malaria incidence in Burundi. This, in turn, emphasizes the need for developing a methodology for mapping malaria risk and delineating those regions that may potentially experience malaria epidemics under climate change in the future.

The paper in hand is intended to map malaria risk in Burundi under climate change up to 2050. For this purpose, a GIS-based model will be developed for mapping malaria through its climatic and topographic determinants. The spatial 
variations of the considered determinants are employed to predict those areas of high malaria risk under expected climate change. Such a prediction is thought that, of great importance due to its role in improving resilience of the country to climate change associated risks.

\section{Case Study}

Burundi is one of the sub-Saharan African countries that is located between $2^{\circ} 20^{\prime}$ and $4^{\circ} 27^{\prime}$ South and between $28^{\circ} 50^{\prime}$ and $30^{\circ} 53^{\prime}$ East [8]. Covering a total area of $27,834 \mathrm{~km}^{2}$, of which $8 \%$ are water surface occupied by Lake Tanganyika; the second largest freshwater lake in the world [27]. The country is one of the most populated countries in East Africa with estimated total population size of 9.8 million inhabitants in 2015. This population primarily lives in rural environments, where urban population represents only about $15 \%$ of the total population [28]. The country is administratively subdivided into 18 provinces (Figure 1), which are subdivided into 46 health districts [29].

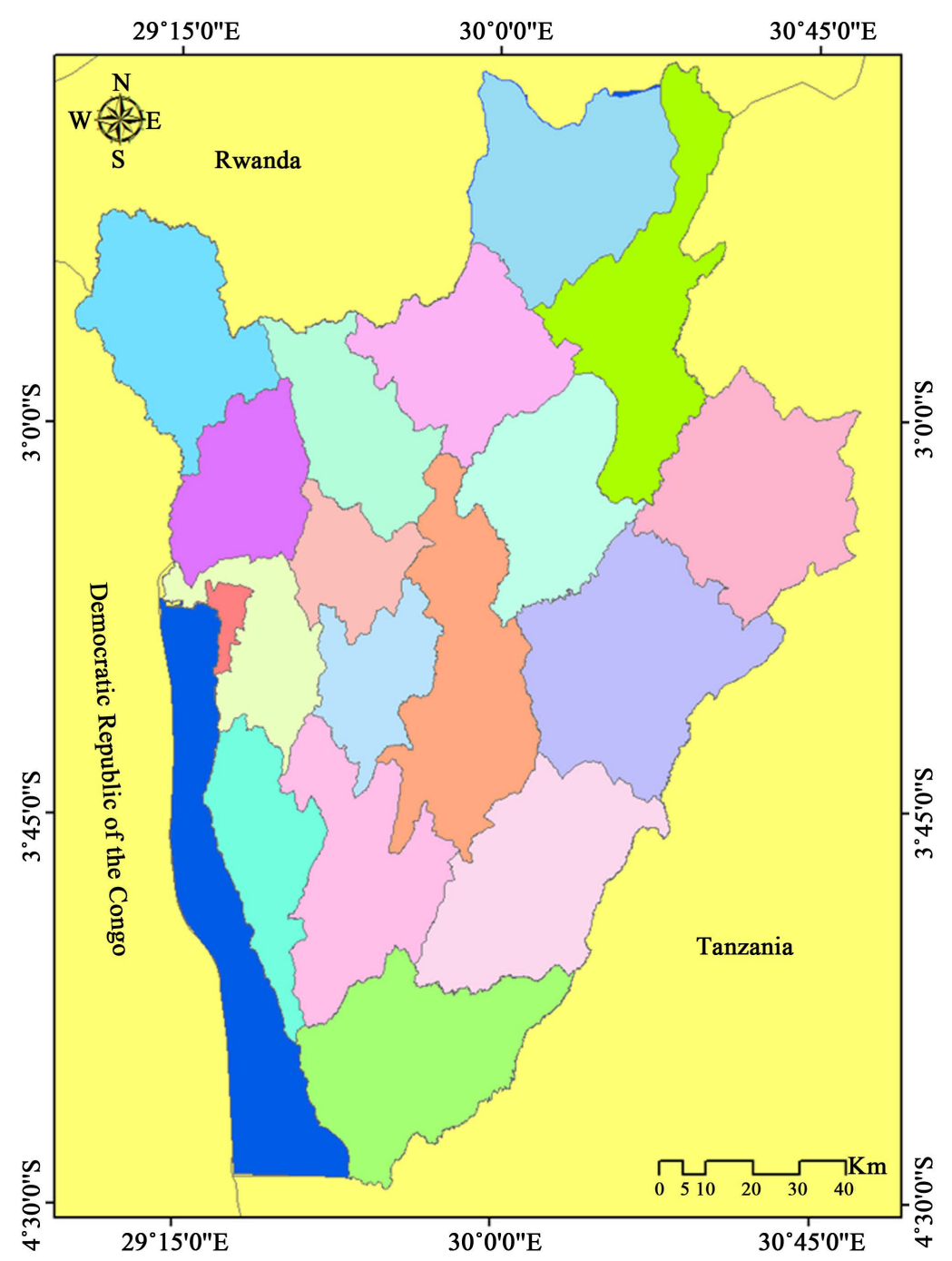

Figure 1. Burundi situation and its provinces. 
Burundi has a mountainous surface with altitude ranging between 775 meters and 2670 meters above mean sea level [8]. The country is dominated by high plateau in the center with an average altitude of 1500 meter above mean sea level [27] (Figure 2). Also, Burundi territory has some plains including Imbo in the West, the Kumoso depression in the East [30]. The varied altitude has considerable impact on temperature, where the highest mountain areas have an average annual temperature of $16^{\circ} \mathrm{C}$, while the central plateau has cool temperature with annual average temperature of $20^{\circ} \mathrm{C}$. Meanwhile, the relatively low areas near Lake Tanganyika has warmer climate with an annual temperature of $23^{\circ} \mathrm{C}$ on average [8].

Most parts of Burundi receive considerable amount of rainfall exceeding 1300 $\mathrm{mm}$ /year. Yet, the rainfall is generally irregular in space and time. Spatially, the north-west parts of Burundi receive heavy rains compared to other parts of the country [8]. Temporally, Burundi climate is characterized by four seasons, a short rainy season (from October to December), a short dry season (January to February), a long rainy season (March to May) and a long dry season (from June to September [30].

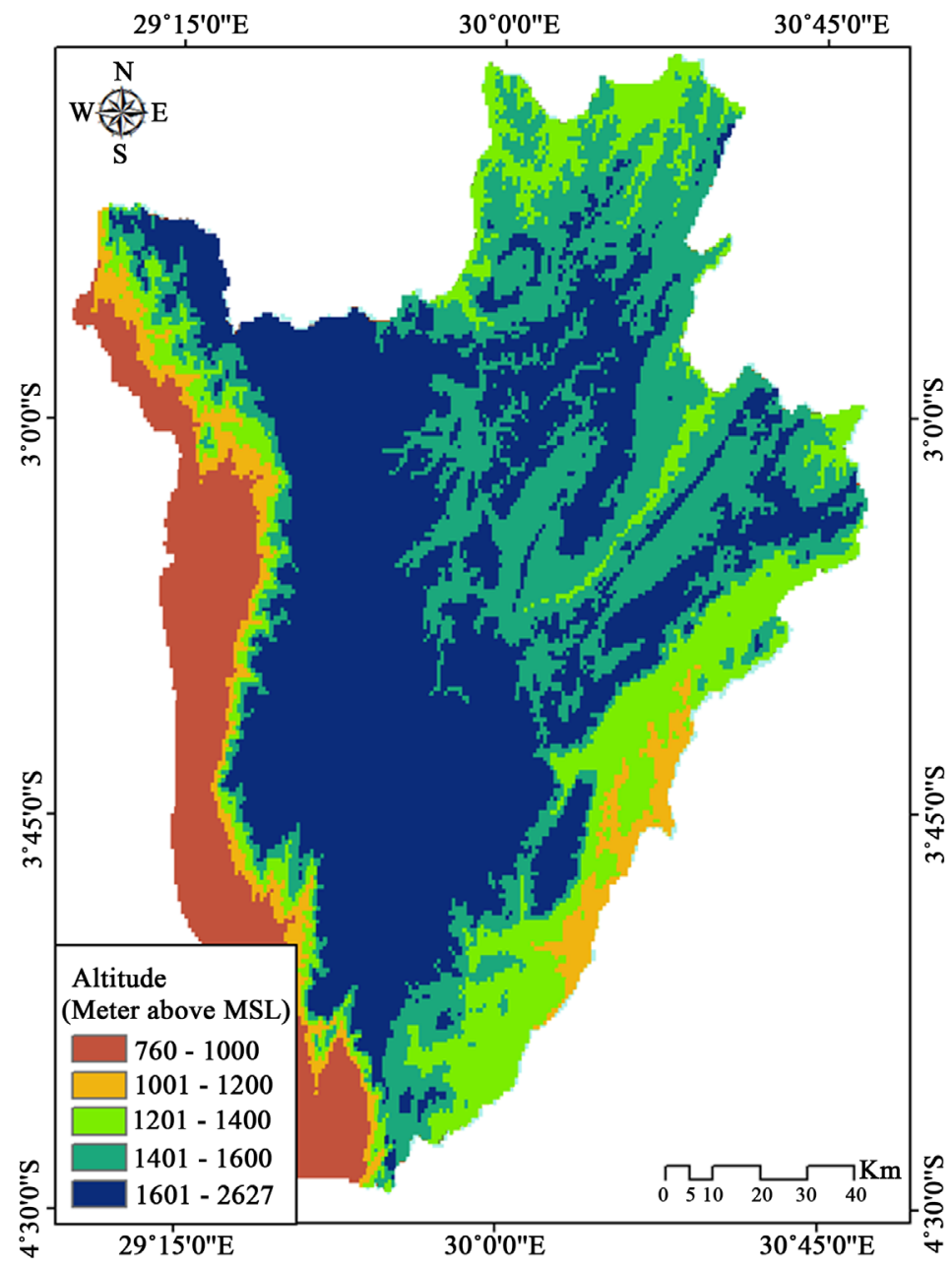

Figure 2. Terrain topography. 


\section{Data and Methodology}

\subsection{Data}

Mapping malaria risk as a function of climatic and topographic conditions requires as a prerequisite identifying those determinants that would be considered. In this respect, a list of seven determinants was developed including: average annual temperature, rainfall, relative humidity, land cover, altitude, terrain slope and distance to wetlands and regularly flooded land. Data on topographic determinants including altitude and land cover was acquired in raster format from DIVA-GIS, which provide a wide range of data in vector and raster formats at country level. Additionally, the base map of Burundi including administrative units at different levels was acquired in vector format [31].

Meanwhile, data on temperature, rainfall and relative humidity as key climatic variables determining malaria risk was obtained from The National Center for Atmospheric Research (NCAR). The obtained data, which was in shapefile format, included historical data for the period 1986-2005 and downscaled data future data under RCP8.5 scenario for the period 2040-2060 [32]. Using ArcGIS (V. 9.3) the acquired data was processed and integrated into a geodatabase for Burundi. In this respect, point feature classes of climatic determinants were interpolated to create raster surfaces representing the spatial variation of these determinants within Burundi territory. Also, slope was derived from altitude raster surface.

Moreover, data on malaria incidence was essential for validation purposes. Accordingly, previous research work and available data sources were surveyed to acquire data on malaria incidence in Burundi. In this respect, data on malaria cases reported by health facilities in 2010 were obtained from the Ministry of Public Health in the service of Epidemiology and health statistics. The district collects health information regularly from health facilities and compiles the data on a monthly basis. The completeness of data in the districts was about $97 \%$ during the study period [33].

\subsection{Methodology}

Using acquired data on various climatic and topographic determinants, malaria risk was mapped according a methodology of four main steps (Figure 3).

1) Evaluating determinants weights

This step involved identifying weight for different climatic and topographic determinants as they don't equally contribute to malaria incidence. For this purpose, Analytic Hierarchy Process (AHP) was applied. AHP is simply a way to assign relative weights for different factors through applying pairwise comparisons [34]. According to pairwise comparisons each factor is evaluated according to an evaluation scale ranging from 1 to 5 (Table 1). As a result of pairwise comparisons and evaluation process, a reciprocal matrix was produced, where each element in the matrix represents the dominance of a certain factor over another in terms of their contribution to malaria risk. Thereafter, each element 


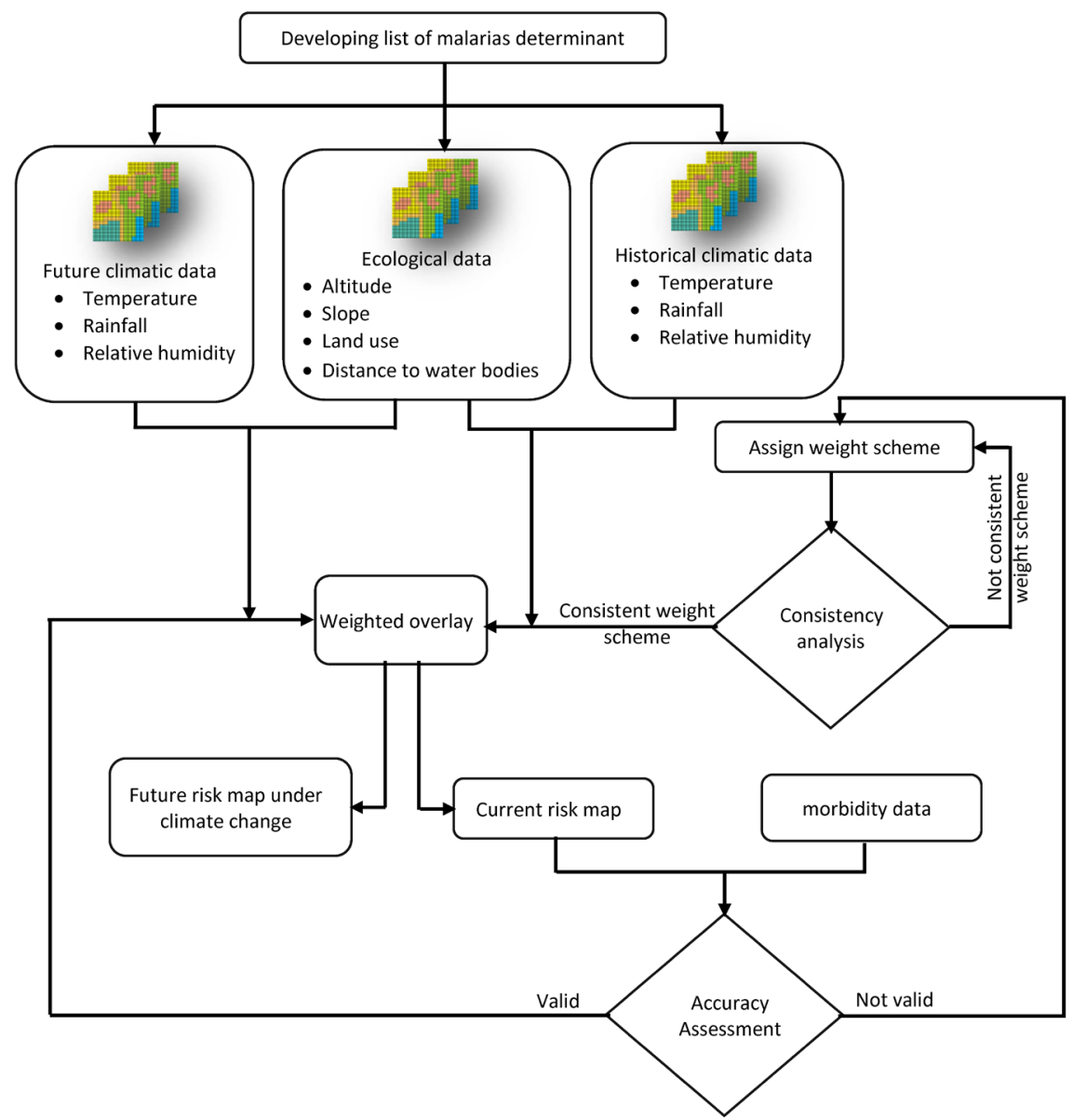

Figure 3. Methodology developed for mapping malaria risk under climate change.

Table 1. Evaluation scale of absolute number.

\begin{tabular}{cl}
\hline Scale & \\
\hline 1 & The two factors contribute equally to malaria risk (Equal relative importance) \\
2 & $\begin{array}{l}\text { The considered factor contributes more slightly to malaria risk } \\
\text { compared to the other factor (slight relative importance) }\end{array}$ \\
3 & $\begin{array}{l}\text { The considered factor contributes moderately to malaria risk } \\
\text { compared to the other factor (Moderate relative importance) }\end{array}$ \\
4 & $\begin{array}{l}\text { The considered factor contributes strongly to malaria risk } \\
\text { compared to the other factor (Strong relative importance) }\end{array}$ \\
& $\begin{array}{l}\text { The considered factor contributes very strongly to malaria risk } \\
\text { compared to the other factor (Very strong relative importance) }\end{array}$
\end{tabular}

in the produced reciprocal matrix was divided by the sum of its column. Finally, the weight of each factor was calculated through averaging across the rows [34] [35].

After estimating weights for all considered determinants, the consistency of the estimated weights was assessed using Consistency Ratio (CR), which was about $9.3 \%$ indicating satisfactory consistency level of the estimated weights as it didn't exceed $10 \%$ level. 
2) Mapping malaria risk under current climatic conditions

This step involved applying Weighted Overlay analysis to combine various climatic and topographic determinants of malaria risk. According to Weighted Overlay analysis the raster surfaces of different considered malaria determinants were reclassified into a common preference scale of different malaria risk levels. Then, each of reclassified raster surfaces is multiplied by its assigned weight, identified in the previous step, then added together (Table 2). As a result, a new raster surface was generated representing different levels of malaria risk at the present according to the considered current climatic and topographic determinants.

3) Assessing accuracy of produced malaria risk map

This step was intended to evaluate the accuracy of the produced malaria risk map compared to morbidity data and identify to what extent the produced malaria risk reflects spatial pattern of malaria incidence in Burundi.

4) Mapping malaria risk under climate change in the future

Using the same weigh scheme, this step included employing Overlay Weighted analysis to map malaria risk under RCP 2.6 and RCP 8.5 scenarios up to 2050 through future climatic data in addition to topographic data. Finally, the produced malaria risk map was compared to current malaria risk map to identify the trend and scale of malaria risk under climate change up to 2050.

\section{Results and Discussion}

Mapping malaria risk means delineating areas that are vulnerable to host breeding sites of malaria vectors and parasites. Such delineation, which was carried out as a function of a number of climatic and topographic determinants of malaria incidence, involved combining these determinants with different weights. As a result, a risk map was produced, in which various parts of Burundi were classified into three levels of risk; low, moderate and high malaria risk.

Generally, the produced malaria risk map, based on current climatic conditions, revealed major proportions of Burundi land surface have moderate-risk level, where the moderate-risk zone dispersed in all parts of Burundi covering about $78.5 \%$ of the total land surface. Meanwhile, the high-risk zone was found to be located mainly in the northern and western parts of Burundi covering about $9.1 \%$ of the total area of Burundi, which are characterized generally by a relatively low altitude, gentle slopes, high relative humidity and receive heavy rains. Such characteristics provide wet and warm conditions that are optimal for malaria vector and parasites. Meanwhile, low-risk zone, which represented about $12.4 \%$ of the total land surface, was found to be distributed in the eastern and southern parts of Burundi (Figure 4).

To assess the accuracy of the produced risk map in delineating current malaria risk as a function of current climatic conditions, the map was compared to spatial pattern of malaria morbidity at district level and the results of previous research work. For this purpose, the spatial extent of high risk zone and health 
Table 2. Classes and weights of climatic and topographic determinants of malaria risk.

\begin{tabular}{|c|c|c|c|c|}
\hline Factor & Weight & Class & Rank & Degree of risk \\
\hline \multirow{5}{*}{$\begin{array}{l}\text { Altitude } \\
\text { (Meter) }\end{array}$} & \multirow{5}{*}{$12 \%$} & $<1200$ & 5 & Very high \\
\hline & & $1200-1300$ & 4 & High \\
\hline & & $1300-1400$ & 3 & Moderately \\
\hline & & $1400-1500$ & 2 & Low \\
\hline & & $>1500$ & 1 & Very low \\
\hline \multirow{5}{*}{$\begin{array}{l}\text { Slope } \\
(\%)\end{array}$} & \multirow{5}{*}{$7 \%$} & $<5$ & 5 & Very high \\
\hline & & $5-10$ & 4 & High \\
\hline & & $10-15$ & 3 & Moderately \\
\hline & & $15-20$ & 2 & Low \\
\hline & & $>20$ & 1 & Very low \\
\hline \multirow{5}{*}{ Land cover } & \multirow{5}{*}{$20 \%$} & Regularly flooded land and cultivated land & 5 & Very high \\
\hline & & Water Bodies & 4 & High \\
\hline & & Shrub or herbaceous land & 3 & Moderately \\
\hline & & Forest land & 2 & Low \\
\hline & & Artificial Surfaces & 1 & Very low \\
\hline \multirow{5}{*}{$\begin{array}{c}\text { Annual } \\
\text { temperature } \\
\text { average }\left({ }^{\circ} \mathrm{C}\right)\end{array}$} & \multirow{5}{*}{$15 \%$} & $>20$ & 5 & Very high \\
\hline & & 20 & 4 & High \\
\hline & & 19 & 3 & Moderately \\
\hline & & 18 & 2 & Low \\
\hline & & $<18$ & 1 & Very low \\
\hline \multirow{5}{*}{$\begin{array}{l}\text { Distance } \\
\text { to wetlands } \\
\quad(\mathrm{km})\end{array}$} & \multirow{5}{*}{$10 \%$} & $>40$ & 5 & Very low \\
\hline & & $20-40$ & 4 & Low \\
\hline & & $10-20$ & 3 & Moderately \\
\hline & & $5-10$ & 2 & High \\
\hline & & $<10$ & 1 & Very High \\
\hline \multirow{5}{*}{$\begin{array}{l}\text { Rainfall } \\
(\mathrm{mm})\end{array}$} & \multirow{5}{*}{$18 \%$} & $>1950$ & 5 & Very high \\
\hline & & $1900-1950$ & 4 & High \\
\hline & & $1850-1900$ & 3 & Moderately \\
\hline & & $1800-1850$ & 2 & Low \\
\hline & & $<1800$ & 1 & Very low \\
\hline \multirow{5}{*}{$\begin{array}{c}\text { Relative } \\
\text { Humidity } \\
(\%)\end{array}$} & \multirow{5}{*}{$18 \%$} & $>82$ & 5 & Very high \\
\hline & & $79-82$ & 4 & High \\
\hline & & $76-79$ & 3 & Moderately \\
\hline & & $73-76$ & 2 & Low \\
\hline & & $<73$ & 1 & Very low \\
\hline
\end{tabular}




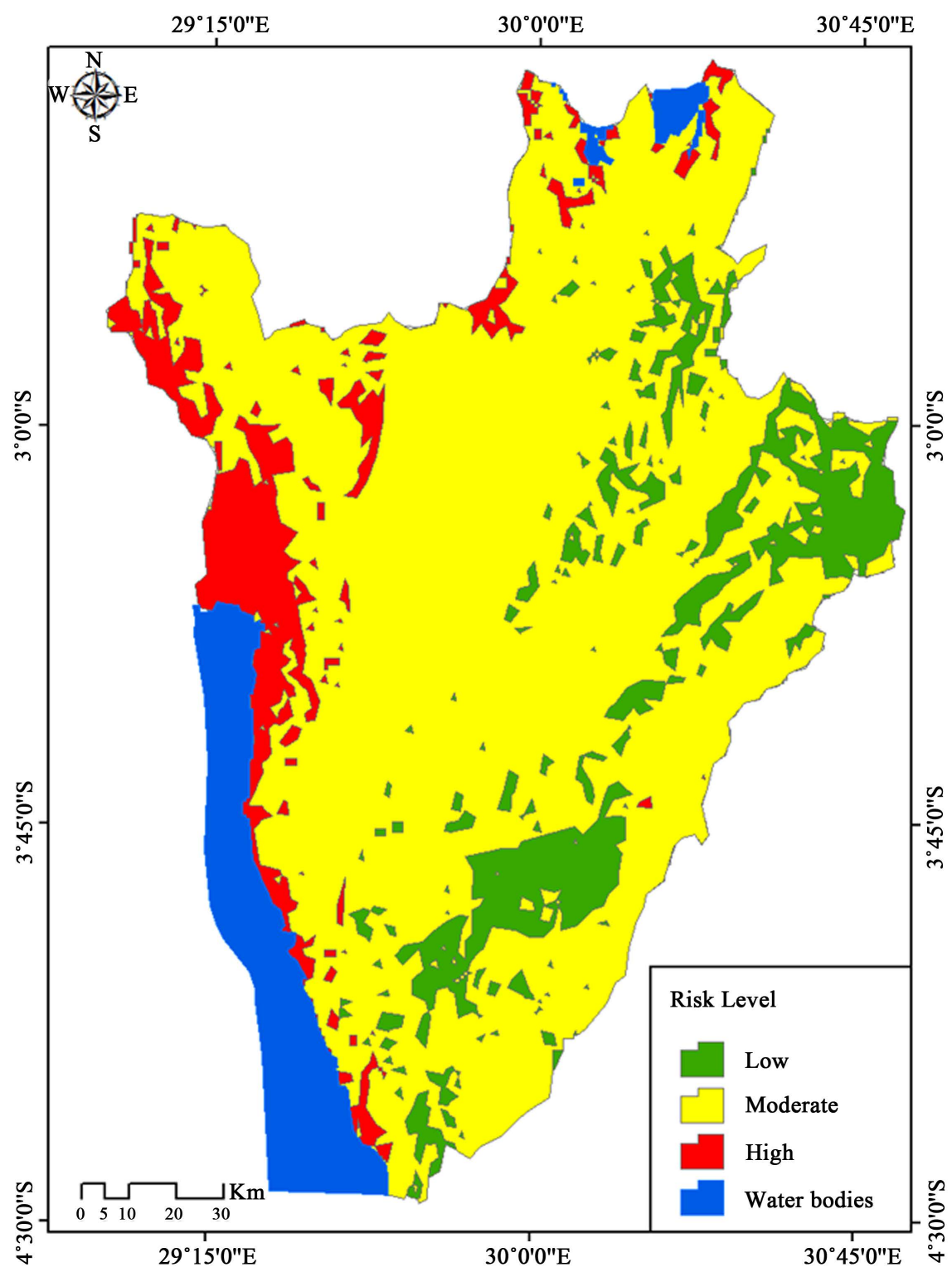

Figure 4. Current malaria risk map.

district were overlaid interest, then, the area of high-risk zone and the no of malaria cases were summarized. It was found that the high-risk zone captured $65 \%$ of the total cases of malaria that are reported at district level in Burundi in 2010 (Table 3). Moreover, high-risk zone included considerable proportions of Kyanza, Kirundi and Cibtoke provinces that were reported by Moise et al., (2016) [23] as hot spots of malaria.

Also, at province level, it was found that the number of malaria cases is positively correlated to the area of high-risk zone and in the top five provinces experiencing high rate of malaria incidence exceeding $1,000,000$ cases in 2010 (Figure 5).

This generally refers to how the produced risk map reflects closely the current situation of malaria risk in Burundi under current climatic conditions, which in 


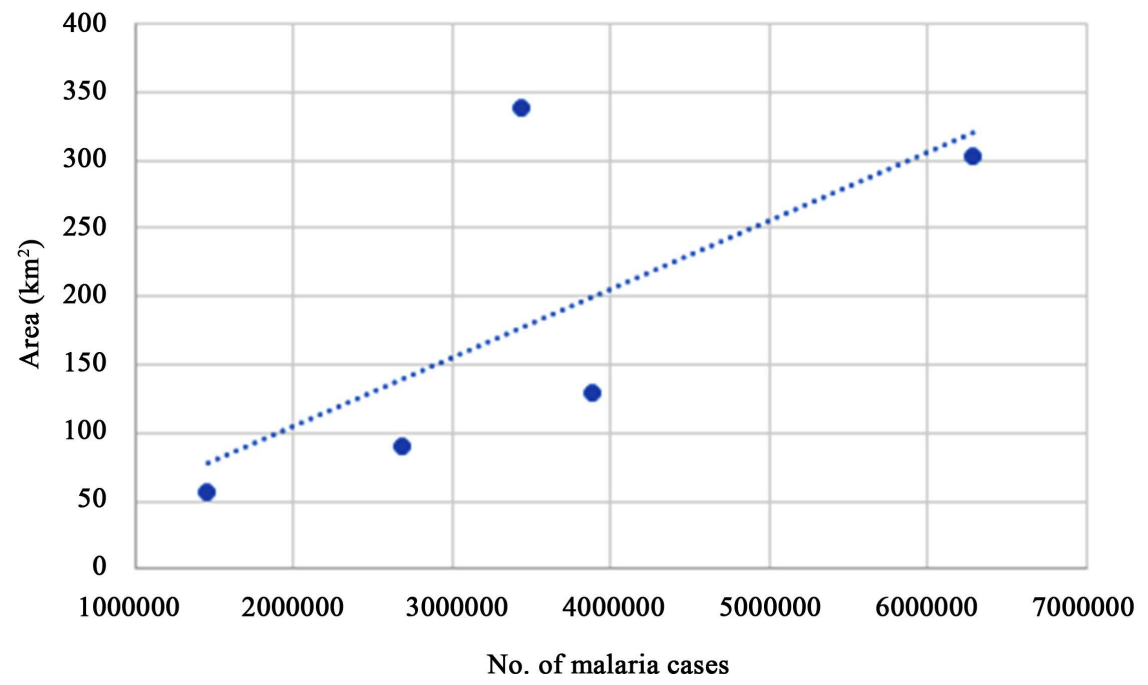

Figure 5. Relationship between number of malaria cases and the area of high-risk zone in the top five health districts in terms of malaria incidence.

Table 3. The number of malaria cases recorded in 2010 within high-risk zone depicted in risk map.

\begin{tabular}{cccc}
\hline Malaria Type & Malaria cases in high risk area & Total cases & $\%$ \\
\hline Confirmed cases & $1,008,952$ & $1,558,004$ & 65 \\
Serious confirmed cases & 76,673 & 104,318 & 73 \\
Pediatric cases & 5990 & 8156 & 73 \\
Total malaria cases & $1,091,615$ & $1,670,478$ & 65 \\
\hline
\end{tabular}

turn, indicates to the validity of the developed approach in delineating malaria risk zones as a function of topographic and climatic conditions. This consequently means that the developed methodology can be employed in mapping malaria risk in the future under climate change.

As for climate conditions under climate change scenarios up to 2050, it is expected that the average annual temperature in Burundi is expected to increase by $0.9^{\circ} \mathrm{C}$ and $1.3^{\circ} \mathrm{C}$ on average, compared to current climatic conditions, up to 2050 under RCP 2.6 and RCP 8.5 scenarios, respectively. Generally, the eastern and southern parts of Burundi are expected to experience the highest level of temperature increase exceeding $1^{\circ} \mathrm{C}$ and $1.5^{\circ} \mathrm{C}$ under the two scenarios, respectively.

Similarly, most parts of Burundi are expected to receive more rainfall under climate change scenarios. The rainfall is expected to increase on average by 97 and $191 \mathrm{~mm}$ /year up to 2050 under RCPs 2.6 and 8.5 scenarios, respectively, compared to current rates of rainfall. Yet, the increase of rainfall will be higher in northern parts of Burundi, where the rainfall is expected to increase by $7 \%$ and $14.5 \%$ under the two scenarios, respectively. Such increasing rainfall is expected to be minimum in the southern parts of Burundi accounting for about 2 and $4 \%$ under the two scenarios, respectively. This means that the northern parts of Burundi are expected to experience wetter conditions under climate change 
up to 2050. In contrast, relative humidity is expected to change slightly under different scenarios ranging between $0.5 \%$ decrease and $1 \%$ increase up to 2050 under RCP 2.6 and RCP 8.5 scenarios, respectively.

Such expected changes in climate variables under different scenarios, particularly, temperature and rainfall, is thought that, will have significant impact on malaria incidence in Burundi in the future. This is especially in eastern parts that are expected to experience higher levels of warming and the northern parts that are expected to experience wetter conditions. This was emphasized by the produced malaria risk maps under RCPs 2.6 (Figure 6) and 8.5 (Figure 7) scenarios up to 2050, which revealed that high-risk zone is expected to expand generally in the northern and eastern parts of Burundi. In this respect, it is expected that, high risk zone will expand to cover about $34.6 \%$ and $44 \%$ of Burundi land surface by 2050 under RCPs 2.6 and 8.5 scenario, respectively. Meanwhile, moderate and low-risk zones are expected to cover together $65.4 \%$ and $65 \%$ of Burundi land surface by 2050 under RCP 2.6 and RCP 8.5 scenarios, respectively.

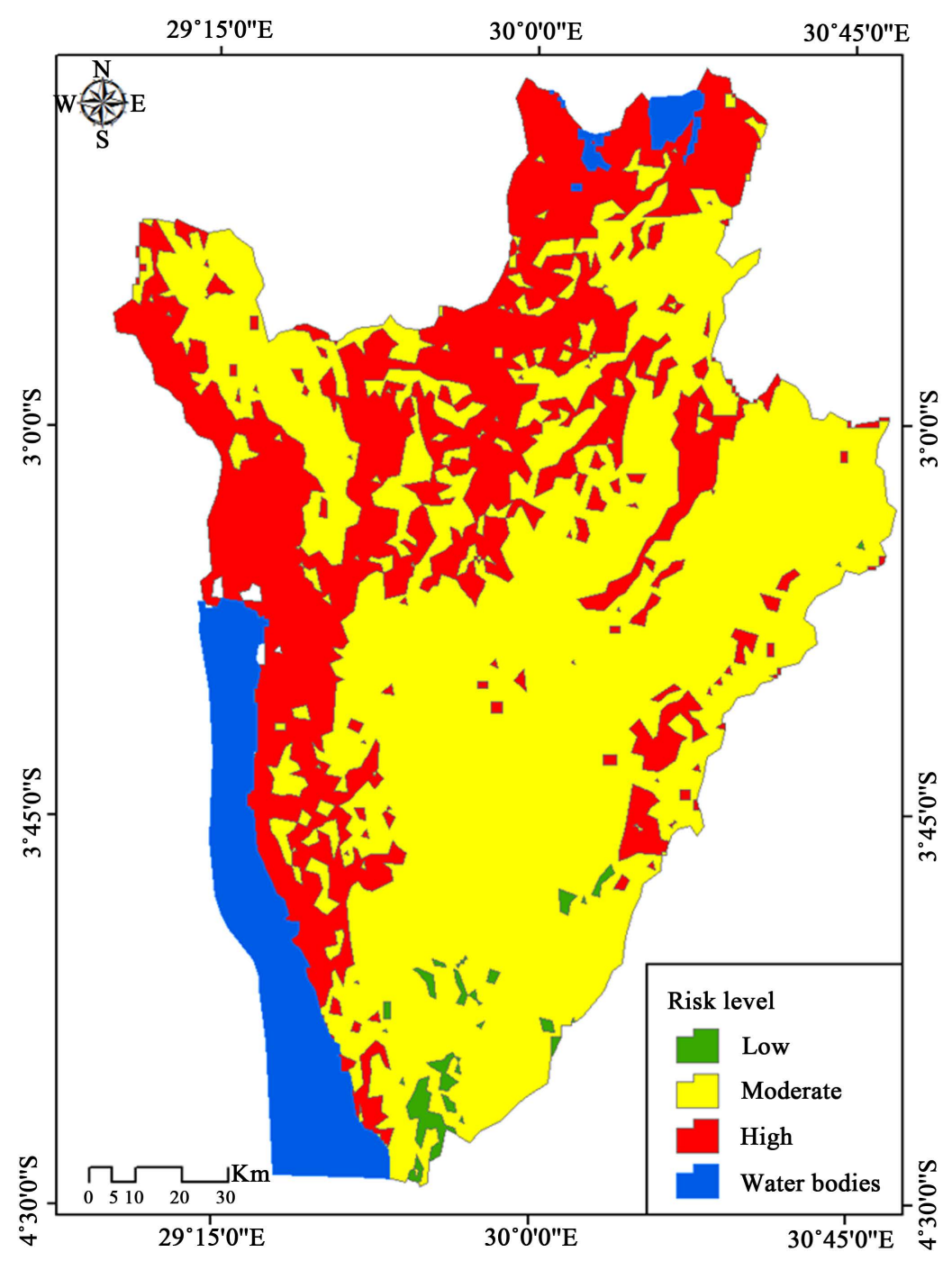

Figure 6. Malaria risk map by 2050 under RCP 2.6 scenario. 


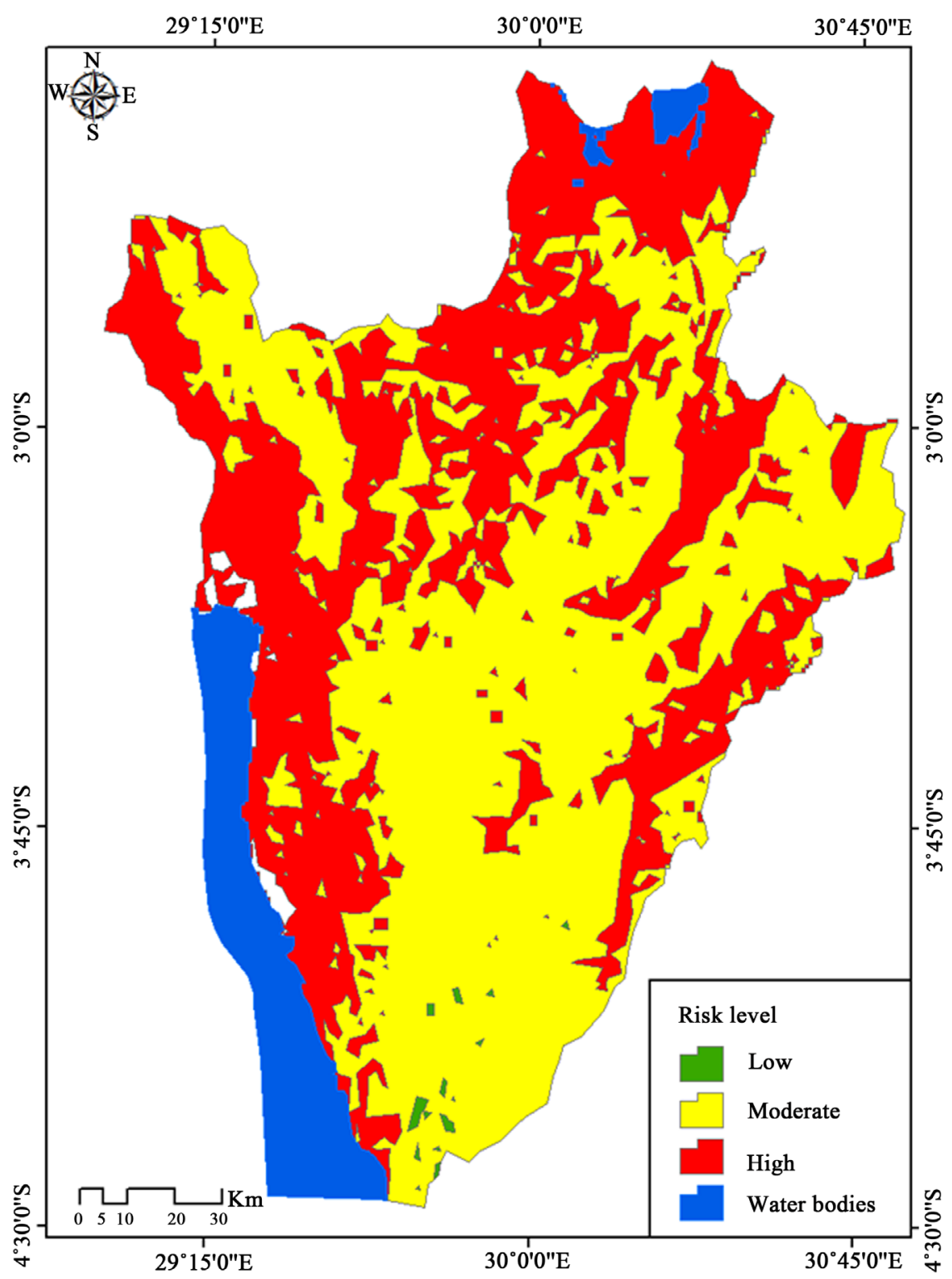

Figure 7. Malaria risk map by 2050 under RCP 8.5 scenario.

To investigate the pattern of change of different risk zones due to expected climate change, the proportions of different risk zones extent in current risk map were compared to those in risk maps under RCPs 2.6 and 8.5 scenarios by 2050 . In this respect, it was found that $26 \%$ and $35 \%$ of total area of currently moderate-risk zone is expected to become high-risk zone under RCP2 2.6 and 8.5 scenarios, respectively. Meanwhile, $11 \%$ and $12 \%$ of total area of currently low-risk zone is expected to become moderate-risk zone under the same two scenarios, respectively (Table 4). This means that about $37 \%$ and $47 \%$ of Burundi are expected to experience exacerbated risk level under RCPs 2.6 and 8.5 scenarios by 2050 .

It should be noted that the decreasing proportions of moderate ad low-risk-zones and increasing proportion of high-risk zone under the climate 
Table 4. Expected proportional change in area of different risk zones due to climate change under RCPs 2.6 and 8.5 scenarios.

\begin{tabular}{ccccccc}
\hline \multirow{2}{*}{ Current risk level } & \multicolumn{3}{c}{ (Under RCP 2.6 scenario) } & \multicolumn{3}{c}{ (Under RCP 8.5 scenario) } \\
\cline { 2 - 7 } & High & Moderate & Low & High & Moderate & Low \\
\hline High & 9 & 0 & 0 & 9 & 0 & 0 \\
Moderate & 26 & 53 & 0 & 35 & 44 & 0 \\
Low & 0 & 11 & 1 & 0 & 12 & 0 \\
\hline
\end{tabular}

change scenarios up to 2050 and exacerbated risk level in considerable proportions of land surface of Burundi highlight the role of climate change in increasing malaria incidence. Such considerably varied proportional area of high-risk zone under the two considered scenarios stresses on the significance of climate change in malaria incidence.

\section{Conclusions}

Mapping malaria risk under expected climate change in the future can contribute largely to improving resilience of Burundi to climate change associated risks and their health implications. In this respect, GIS can play a crucial role in mapping malaria risk under different scenarios of climate change and identify hot sports of malaria incidence that will need to intervention and control measure.

The developed GIS-based methodology for mapping malaria under climate change revealed that considerable parts of Burundi, particularly northern parts, will be highly vulnerable to malaria risk in the future under different scenarios of climate change.

The accuracy of mapping process of malaria risk under climate change is determined by availability of data on malaria determinants currently and in the future. Also, to improve the accuracy of mapping process, there is a need to apply an integrated analysis considering, in addition to topographic and climatic determinants, socioeconomic determinants of malaria such as income, population density, access to health services and effectiveness of malaria control measures, etc. Yet, this entails projecting these variables in the future as a prerequisite of such integrated analysis.

\section{Acknowledgements}

This research work is part of a research project sponsored by the IDRC-Canada for establishing Alexandria Research Center for Adaptation to Climate Change (ARCA) at the University of Alexandria, Egypt.

\section{References}

[1] Beck-Johnson, L.M., et al. (2017) The Importance of Temperature Fluctuations in Understanding Mosquito Population Dynamics and Malaria. Royal Society Open Science, 4, 160969. 
[2] WHO (2016) World Malaria Report 2016. Geneva.

[3] WHO (2017) Media Centre. Geneva

[4] Craig, M.H. (1999) A Climate-Based Distribution Model of Malaria Transmission in Sub-Saharan Africa. Parasitology Today, 15, 105-111. https://doi.org/10.1016/S0169-4758(99)01396-4

[5] Hay, S.I., et al. (2002) Climate Change and the Resurgence of Malaria in the East African Highlands. Nature, 415, 905-909. https://doi.org/10.1038/415905a

[6] Nkurunziza, H., Gebhardt, A. and Pliz, J. (2011) Geo-Additive Modelling of Malaria in Burundi. Malaria Journal, 10, 234. https://doi.org/10.1186/1475-2875-10-234

[7] Hoshen, M.B. and Morse, A.P. (2004) A Weather-Driven Model of Malaria Transmission. Malaria Journal, 3, 32.

[8] Nkurunziza, H., Gebhardt, A. and Pilz, J. (2010) Bayesian Modelling of the Effect of Climate on Malaria in Burundi. Malaria Journal, 9, 114. https://doi.org/10.1186/1475-2875-9-114

[9] Odongo-Aginya, E., et al. (2005) Relationship between Malaria Infection Intensity and Rainfall Pattern in Entebbi Peninsula, Uganda. African Health Science, 5, 238-245.

[10] Olson, S.H., et al. (2009) Links between Climate, Malaria, and Wetlands in the Amazon Basin. Emerging Infectious Diseases, 15, 659-662. https://doi.org/10.3201/eid1504.080822

[11] Jhajharia, D., et al. (2013) Influence of Climate on Incidences of Malaria in the Thar Desert, Northwest India. International Journal of Climatology, 33, 312-325. https://doi.org/10.1002/joc.3424

[12] Patz, J.A. and Olson, S.H. (2006) Malaria Risk and Temperature: Influences from Global Climate Change and Local Land Use Practices. Proceedings of the National Academy of Sciences, 103, 5635-5636. https://doi.org/10.1073/pnas.0601493103

[13] Gebreslasie, M.T. (2015) A Review of Spatial Technologies with Applications for Malaria Transmission Modelling and Control in Africa. Geospatial Health, 10, 239-247. https://doi.org/10.4081/gh.2015.328

[14] Paaijmans, K.P., et al. (2010) Influence of Climate on Malaria Transmission Depends on Daily Temperature Variation. PNAS, 107, 15135-15139.

https://doi.org/10.1073/pnas.1006422107

[15] Paaijmans, K.P., Read, A.F. and Thomas, M.B. (2009) Understanding the Link between Malaria Risk and Climate. PNAS, 106, 13844-13849.

https://doi.org/10.1073/pnas.0903423106

[16] Maxwell, C.A., et al. (2003) Variation of Malaria Transmission and Morbidity with Altitude in Tanzania and with Introduction of Alphacypermethrin Treated Nets. Malaria Journal, 2.

[17] Balls, M.J., et al. (2004) Effect of Topography on the Risk of Malaria Infection in the Usambara Mountains, Tanzania. Transactions of the Royal Society of Tropical Medicine and Hygiene, 98, 400-408.

[18] Bødker, R., et al. (2003) Relationship between Altitude and Intensity of Malaria Transmission in the Usambara Mountains, Tanzania. Journal of Medical Entomology, 40, 706-717. https://doi.org/10.1603/0022-2585-40.5.706

[19] Tuyishimire, J., et al. (2017) Spatial Modelling of Malaria Risk Factors in Ruhuha Sector in the East of Rwanda. Rwanda Journal, 1.

[20] Hanafi-Bojd, A.A., et al. (2012) Spatial Analysis and Mapping of Malaria Risk in an Endemic Area, South of Iran: A GIS Based Decision Making for Planning of Control. Acta Tropica, 122, 132-137. 
[21] Dalrymple, U., Mappin, B. and Gething, P.W. (2015) Malaria Mapping: Understanding the Global Endemicity of Falciparum and Vivax Malaria. BMC Medicine, 13. https://doi.org/10.1186/s12916-015-0372-x

[22] Booman, M., et al. (2000) Using a Geographical Information System to Plan a Malria Control Program in South Africa. Bulletin of World Health Organization, 78, 1438-1444.

[23] Moise, I.K., et al. (2016) Seasonal and Geographic Variation of Pediatric Malaria in Burundi: 2011 to 2012. International Journal of Environmental Research and Public Health, 13, 425. https://doi.org/10.3390/ijerph13040425

[24] Confalonieri, U., et al. (2007) Human Health. In: Parry, M.L., Canziani, O.F., Palutikof, J.P., van der Linden, P.J. and Hanson, C.E., Eds., Climate Change 2007: Impacts, Adaptation and Vulnerability, Contribution of Working Group II to the Fourth Assessment Report of the Intergovernmental Panel on Climate Change, Cambridge, 391-431.

[25] Tonnang, H.E., Kangalawe, R.Y. and Yanda, P.Z. (2010) Predicting and Mapping Malaria under Climate Change Scenarios: The Potential Redistribution of Malaria Vectors in Africa. Malaria Journal, 9, 111. https://doi.org/10.1186/1475-2875-9-111

[26] Rosenthal, J. (2009) Climate Change and the Geographic Distribution of Infectious Diseases. EcoHealth, 6, 489-495. https://doi.org/10.1007/s10393-010-0314-1

[27] Worldatlas (2016) Burundi Geography. http://www.worldatlas.com/webimage/countrys/africa/burundi/biland.htm

[28] UN United Nation (2017) Deographic Year Book. https://unstats.un.org/Unsd/demographic/products/dyb/dyb2.htm

[29] Ministère de la Sante Publique et de la lute contre le Sida Direction National du Système d'Information Sanitaire, la Carte sanitaire version Mai 2016. [The Sanitary Map Version May 2016.] https://www.minisante.bi/images/DSNIS/rapports/carte\%20sanitaire\%20Burundi\% 20mai2016.pdf

[30] Mphfa (Undated) National Health Development Plan 2011-2015. Ministry of Public Health and Fighting AIDS.

[31] DIVA-GIS (2017) Free Spatial Data by Country. http://www.diva-gis.org/gdata

[32] NCAR (2014) GIS Data Services Are Provided by NCAR GIS Program through Climate Change Scenarios Version 2.0, 2012. http://www.gisclimatechange.org

[33] Ministère de la Sante Publique et de la lute contre le Sida Direction National du Système d'Information Sanitaire Publique, Annuaire Statistique des Donnees des Centres de Sante et des Hôpitaux pour L'annee 2010. 2011, Bujumbura. [Statistical Data Directory of Health Centers and Hospitals for the Year 2010.]

[34] Whitaker, R. (2007) Validation Examples of the Analytic Hierarchy Process and Analytic Network Process. Mathematical and Computer Modelling, 46, 840-859.

[35] Uyan, M. (2013) GIS-Based Solar Farms Site Selection Using Analytic Hierarchy Process (AHP) in Karapinar Region, Konya/Turkey. Renewable and Sustainable Energy Reviews, 28, 11-17. 